\title{
新冠疫情下 ESG 因素对 A 股上市公司的影响
}

\author{
Influence of ESG Factors on A-Shares Listed Companies Under Covid-19 Epidemic \\ 陈周永 \\ Zhouyong Chen
}

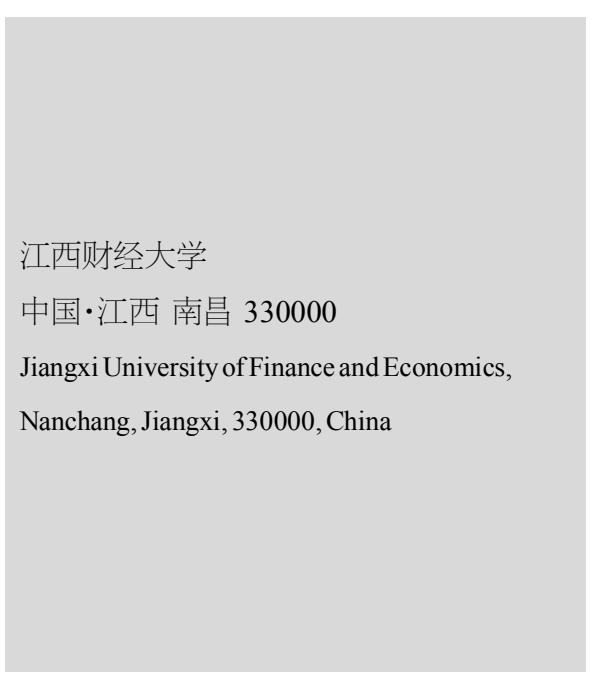

【摘要】新冠疫情给 $\mathrm{A}$ 股市场带来了很大的冲击, 论文通过探讨不同 ESG 评级的上市 公司在疫情期间的表现得出: 在疫情期间, 相对于 ESG 表现较差的上市公司,ESG 表现好 的上市公司呈现出较高的收益率和稳健的风险水平。最后, 就 ESG 在中国的发展提出了建 设性的建议。

【Abstract】The COVID-19 epidemic had a great impact on the A-share market. We discussed the performance of listed companies with different ESG ratings during the epidemic. The results show that listed companies with better ESG performance showed relatively higher returns and stable risk levels than those with poor ESG during the epidemic. Finally, this paper puts forward constructive suggestions on the development of ESG in China.

【关键词】ESG; 新冠疫情; $\mathrm{A}$ 股; 上市公司

【Keywords 】ESG; COVID-19 epidemic; A-shares; listed company

【DOI】10.36012/emr.v2i3.1796

\section{1 引言}

奥利兹基等(2001)发现,企业 ESG 方面的表现与其风险 成显著负相关关系。佐恩等(2016)发现 ESG 表现较差的企业 被投资者卖空的风险显著高于 $\mathrm{ESG}$ 表现较好的企业。施懿宸 等(2020)认为瑞幸咖啡财务造假的背后是 ESG 的缺失。布拉 默等(2006)研究发现公司在环境保护方面的社会责任履行程 度与股票收益率呈现出负相关关系。格雷(1995)指出环境治 理成本会降低企业生产效率,给企业带来经济损失。由此可以 看出, 国际上的相关研究有着不同的结果, 另外, 关于 ESG 因 素对上市公司股票收益率和风险水平的研究尚少。

\section{ESG 的概念}

$\mathrm{ESG}$ 是环境、社会和治理三个概念的缩写, 是一种关注企 业环境、社会和治理绩效的企业评价标准 ${ }^{[1]}$ 。环境包括气候、

【作者简介】陈周永(1995 ), 男, 广东英德人, 江西财经大学研究 生, 从事国际商务方向研究。
水资源、生物多样性、土地利用等有毒排放物等; 社会指的是 公司在人力资本、劳动管理、产品安全和数据安全等方面的表 现; 公司治理是指公司会计、商业道德、税收透明度和腐败等 方面的表现。目前, ESG 主要评估机构有 MSIC 和富时罗素、 华证和道融绿等机构。

\section{3 疫情期间 ESG 因素与投资风险的分析}

华证指数在今年 1 月 31 日发布 $\mathrm{A}$ 股上市公司的评级， 评级分为 $\mathrm{AAA}$ 到 $\mathrm{C}$ 级, 结合疫情的实际发展动态和华证指 数发布的时间点, 论文选取了 2 月 1 日到 4 月 30 日为分析 区间。

根据 Wind 的数据, 对 66 个行业进行分析。首先将每个 行业的按照华证 ESG 的等级评分排名, 然后选取了 ESG 排名 靠前的 $25 \%$ 和排名最后的 $25 \%$ 的上市公司数据进行对比。如 图 1 所示, ESG 排名靠前的 $25 \%$ 的上市公司的最大回撤率 为 $-17.05 \%$, 而在 ESG 排名最后的 $25 \%$ 的公司最大回撤率为$22.31 \%$ 。可以看出, 在 ESG 排名靠前的 $25 \%$ 上市公司的风险 
水平相对较低。

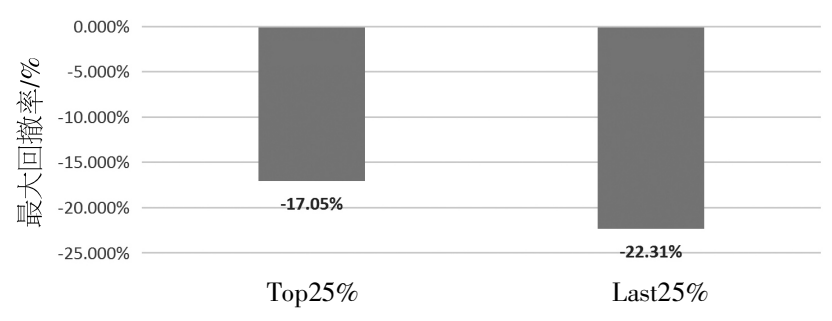

图 1 疫情期间最大回撤率对比

另外,考虑到疫情对于不同的行业有着不同的影响,所以 有必要对于不同行业的情况进行分析, 对比每个行业 ESG 排 名靠前的 $25 \%$ 上市公司和 ESG 排名最后的 $25 \%$ 的上市公司, 如图 2 所示, 发现最大回撤率前者小于后者的行业个数有 58 个, 占比达到了 $87.88 \%$ 。也就是说, 在绝大部分的行业中, 相 对于 ESG 表现较差的上市公司, ESG 表现良好的上市公司呈 现出相对较低的风险水平。

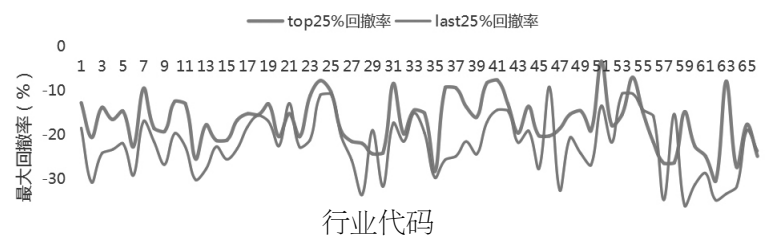

图 266 个行业最大回撤率对比

\section{4 疫情期间 ESG 因素与 A 股收益的分析}

在收益率方面, 选取了 66 个行业上市公司, 根据 ESG 等 级排名靠前的 $25 \%$ 的收益率和 ESG 等级排名最后的 $25 \%$ 的 收益率的平均值对比, 如图 3 所示。结果显示, ESG 排名靠前 的 $25 \%$ 的企业的收益率为 $2.70 \%$, 而 ESG 排名最后的 $25 \%$ 的 收益率为 $0.65 \%$,也就是说, 疫情期间 ESG 表现良好的企业 有着相对较高的收益率。投资者对于 ESG 评分较高的企业表 现出更大的信心。

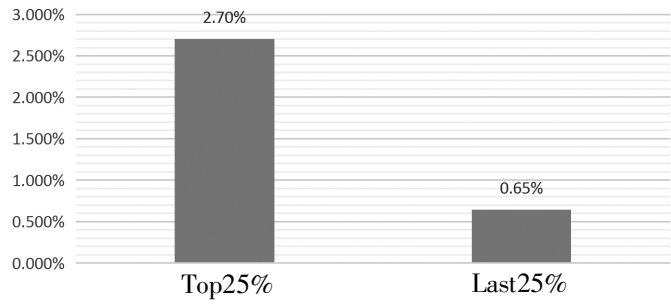

图 3 疫情期间收益率对比

从细分的角度来看, 如图 4, 在 66 个行业中,ESG 排名靠 前的 $25 \%$ 的上市公司的收益率大于 ESG 排名最后的 $25 \%$ 的 行业个数有 53 个,也就是说新型冠状疫情期间,在 $80.30 \%$ 的 行业中, ESG 表现较好的上市公司有着更高的收益。

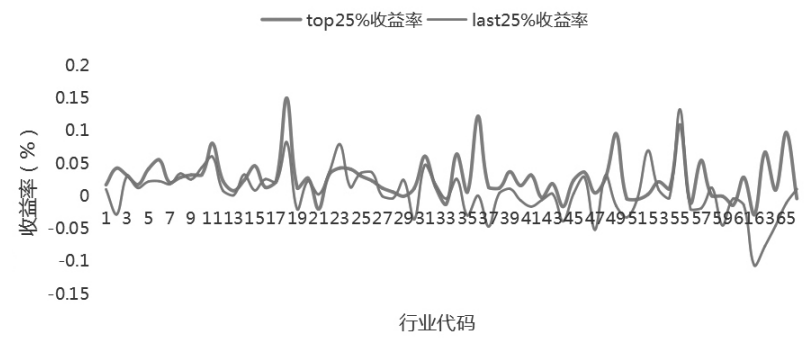

图 466 个行业收益率对比

具体来看, 以房地产业为例, 今年 1 月 31 日华证指数公 布了 ESG 数据, 覆盖房地产业 121 家上市公司, 如表 1 所示, ESG 排名靠前的 $25 \%$ 的房地产公司的收益率为 $1.69 \%$ ，最大 回撤率为 $-12.78 \%$; 而 ESG 排名最后的 $25 \%$ 的上市公司的收 益率为 $1.01 \%$, 最大回撤率为 $-18.50 \%$ 。在前 $25 \%$ 的上市公司 中,包括万科等 31 家上市公司,在最后 $25 \%$ 的上市公司中包 括世茂股份等 31 家上市公司。结果表明:在房地产业中, ESG 表现较好的上市公司呈现出相对较高的收益率和稳健的风险 水平。

表 1 收益率和最大撤回率综合对比

\begin{tabular}{c|c|c|c|c}
\hline 房地产行业 & 公司数目 & 最小评级 & 收益率 & 最大回撤率 \\
\hline 前 $25 \%$ & 31 & $\mathrm{AA}$ & $1.69 \%$ & $-12.78 \%$ \\
\hline 最后 $25 \%$ & 31 & $\mathrm{~B}$ & $1.01 \%$ & $-18.5 \%$ \\
\hline
\end{tabular}

总的来看, 无论从宏观视角还是微观角度分析, 在疫情期 间, ESG 表现较好的上市公司呈现出相对较高的收益率和相 对稳健的风险水平。

\section{5 建议}

\section{1 积极推动 $E S G$ 披露制度由主动披露过渡到}

\section{强制披露}

MSCI (2016)发现,相对于无政府主导信息披露的上市 公司,有政府主导的上市公司 ESG 评分平均要高 $33 \%$ 。2018 年中国证券监督管理委员会发布《上市公司公司治理准 则》, 要求上市公司按照法律和有关部门的规定披露 ESG 的 相关信息，显然中国政府也在积极推动 ESG 信息的披露 ${ }^{[2]}$ 。 就目前到 2019 年数据来看，有 900 多家上市公司披露了社 会责任报告，仅占 A 股 $26 \%$ 的上市公司，覆盖范围相对较 低,所以必须要求那些不按照规则披露信息的公司作出合理 解释。另外, 对于积极披露信息和 ESG 评分良好的企业, 在 一定程度上给予相应的鼓励和支持, 比如在招标和税收减免 方面进行鼓励以及在信贷和融资方面提供相应的便利政策。 逐步完善ESG 披露规则，积极推进强制性 ESG 信息披露体 系的建立是大势所趋。 


\section{2 确保 ESG 评级披露的真实性和可靠性}

$\mathrm{ESG}$ 作为非财务评估指标，越来越受到众多投资者的青 睐。2019 年商道融绿在对 2637 位个人投资者的调查中发现, 有 $86 \%$ 的个人投资者会考虑 ESG 因素; 另外, 600 万以上的 高净值投资人群更加看重 ESG 因素。虽然, ESG 投资理念在 中国的发展起步较晚，但近几年来在中国得到了快速的发 展, 无论是个人投资者或者是投资机构都越来越重视 ESG 因 素在投资决策的作用。现有的关于 A 股 ESG 评级机构主要 有富时罗素、华证指数、社会价值投资联盟和商道融绿等。但 是这些机构评估的方法和指标存在着一定的差异, 而且作为 第三方的评估机构,在确保 ESG 评级的真实性和可靠性方面 有所欠缺。如果由政府机构来主导监督,第三方评估机构所 发布的 ESG 评级会更具真实性和可靠性,进而给投资者带来 更大的参考价值以更好地促进股票市场的可持续发展。

\section{3 多方努力构建、形成良性循环}

ESG 投资理念并非仅限于股票市场中，同时也存在于公
募基金、银行理财、信贷和资产管理等方面。所以,对于投资者 或者投资机构来说,要积极表达对于 ESG 信息的需求, 从而 促使 ESG 信息的披露和促进评级机构的发展。对于中国企业 来说,要积极承担起 ESG 信息披露的责任, 努力承担起对环 境、社会和公司治理的责任,这样才能增强投资者对于上市公 司的信任 ${ }^{[3]}$ 。对于中国政府机构来说, 要主动发挥主导作用, 制定科学详尽的 ESG 信息披露规则, 发挥好对于上市公司和 第三方评级机构的监督职责。最后,通过各方的共同努力形成 良性循环，进而让中国金融市场在可持续发展中迈出更坚实 的步伐。

\section{参考文献}

[1]马喜立.ESG 投资策略具备排雷功能吗? 一一基于中国 A 股 市场的实证研究[J].北方金融,2019(5):14-19.

[2]施懿宸，杨晨辉,包婕. 瑞幸的“品格”[J]. 封面报道,2020(4):35-38. [3]陈静.ESG 与企业财务绩效相关性研究[D].北京:对外经济贸 易大学, 2019 .

\section{（上接第 69 页）}

的稳定和秩序起到了很重要的作用。孔子花费了很多年的时 间创儒学和推广儒学思想,经过不断的推广、传播,进而形成 中国人固有的一种思维模式, 直到现在其影响仍然深远！

随着时代的发展,一些新的模式被吸收和发展出来,如以 民主、自由、法制为核心的西方民主社会模式, 以苏联模式为 主导的社会主义思想，和在两者基础之上发展融合的中国特 色的社会主义模式。然而几千年过去,孔子的儒学仍然没有完 全消失,一些有用的地方仍然保留下来,形成一种道德模式影 响着这个社会, 这是思想转变成文化的力量和作用。

安全管理体系直接产生于 ISM 的思想,这种思想首先来 源于 ISO 9000 质量管理体系的思想,现在已经在现代管理学 思想上应用 ${ }^{[2]}$ 。一个新的东西产生和应用需要一个过程, NSM 规则和 SMS 体系在中国同样需要一个传播和被实践检验的 过程。安全管理体系, 是船员和航运公司的一种行为准则, 从 建立、推广到成为一种自觉的行为规范需要一个过程,将在实 践中得到检验, 在实践中得到传播, 在实践中得到认可, 经过 几年,十几年甚至几十年,这种文化会深入人心, 成为一种习 惯,成为一种自觉意识。在这个过程中,海事主管机关起着全 面的主导作用,作为管理公司来说, 虽然只在航运业整体中起
到局部的作用,但它是航运业中不可缺少的一个组成部分, 所 以管理公司更应站在海事主管部门的立场发挥管理的社会作 用。各航运公司和管理公司实践的过程就是一个传播的过程, 反 过来,安全管理体系在中国传播的过程,也是实践的过程。

\section{5 结语}

任何理论都需要通过实践来检验是否有效。实践证明,随 着 NSM 规则多年的推行,在长时间, 大面积和数量多的统计 学范围内,船舶事故率明显降低。

以 NSM 规则为核心的体系化管理, 是一个系统工程, 需 要海事部门的有效监管, 需要整合各种社会资源, 不断传播安 全体系文化, 约束船员的行为规范, 促进船舶安全营运, 促进 为航运业服务的各种公司的健康发展，优化航运业 “生态环 境”, 经过五年、十年、二十年, NSM 规则必将会深入船员的内 心,持久地保证船舶安全,保护水域环境。

\section{参考文献}

[1]交海发[2001]383 号.中华人民共和国船舶安全营运和防止污 染管理规则(试行)[Z].北京:中华人民共和国交通部,2001.

[2] 中华人民共和国长江海事局.国内安全管理规则文件汇编[M]. 北京:中国海事局交通安全管理体系审核中心,2007. 